\title{
Association of the rs3743205 variant of DYX1C1 with dyslexia in Chinese children
}

\author{
Cadmon KP Lim ${ }^{1}$, Connie SH Ho${ }^{2}$, Crystal HN Chou ${ }^{2}$ and Mary MY Waye ${ }^{1 *}$
}

\begin{abstract}
Background: Dyslexia is a learning disability that is characterized by difficulties in the acquisition of reading and spelling skills independent of intelligence, motivation or schooling. Studies of western populations have suggested that DYX1C1 is a candidate gene for dyslexia. In view of the different languages used in Caucasian and Chinese populations, it is therefore worthwhile to investigate whether there is an association of DYX1C1 in Chinese children with dyslexia.

Method and Results: Eight single nucleotide polymorphisms (SNPs) were genotyped from three hundred and ninety three individuals from 131 Chinese families with two which have been reported in the literature and six tag SNPs at DYX1C1. Analysis for allelic and haplotypic associations was performed with the UNPHASED program and multiple testing was corrected using false discovery rates. We replicated the previously reported association of rs3743205 in Chinese children with dyslexia $\left(p_{\text {corrected }}=0.0072\right.$ ). This SNP was also associated with rapid naming, phonological memory and orthographic skills in quantitative trait analysis.

Conclusion: Our findings suggest that DYX1C1 is associated with dyslexia in people of Chinese ethnicity in Hong Kong.
\end{abstract}

\section{Introduction}

Developmental dyslexia (DD) is a learning disability that is characterized by difficulties in the acquisition of reading and spelling skills independent of intelligence, motivation or schooling. It is the most common form of learning disability (about $80 \%$ of learning disabilities is due to dyslexia) and affects about $5-10 \%$ of school children worldwide $[1,2]$. Studies delineating genetic factors in developmental dyslexia have identified several putative loci $(D Y X 1$ DYX9) and candidate genes (KIAA0319, DYX1C1, DCDC2 and ROBO1) [3]. Recently, associations with the MRPL19/ C2ORF3 genes of DYX3 locus, KIAA0319L of DYX8 locus and GRIN2B gene have also been reported [4-6].

$D Y X 1 C 1$ is the first candidate susceptibility gene of dyslexia to be identified. A cytogenetic study revealed that two chromosome translocations $[\mathrm{t}(2 ; 15)(\mathrm{q} 11 ; \mathrm{q} 21)$ and $\mathrm{t}(2 ; 15)(\mathrm{q} 13 ; \mathrm{q} 22)]$ in the $D Y X 1$ locus co-segregated with dyslexia [7]. Taipale et al. [8] confirmed these translocations in another dyslexic cohort, and further reported

\footnotetext{
* Correspondence: mary-waye@cuhk.edu.hk

${ }^{1}$ Croucher Laboratory for Human Genomics, School of Biomedical Sciences,

The Chinese University of Hong Kong, Shatin, N.T, Hong Kong

Full list of author information is available at the end of the article
}

two functional variants -3G/A (rs3743205) and 1249G/T in DYX1C1 associated with dyslexia. Rare variant -3A was proposed to be able to alter the Elk-1 transcription factor binding site and affect translation initiation, while $1249 \mathrm{~T}$ caused a nucleotide transversion to result in a truncated protein [8].

The association of this same variant -3A has been shown to be a quantitative trait of short-term memory but it has not been shown to be associated with categorical DD [9]. Positive findings were also found in other Caucasian population cohorts but biased transmission was shown in other polymorphisms and in the common allele of -3G/A or 1249G/T [10-12]. Wigg et al. [10] reported significant association for the common -3G allele with readingrelated phenotypes in single marker analysis and biased transmission of rs11629841 and the common haplotype of 3G/1249G in categorical DD. In Scerri's study [11], a marginally significant association was shown between the common allele (1249G) and common haplotype of the two markers (-3G/1249G) and poorer performance for the phenotypic measure of orthographic coding choice (OCchoice). Dahdouh et al. [12] only showed a common haplotype (G/G/G) of three markers (rs3743205/rs3743204/
Ciomed Central

(C) 2011 Lim et al; licensee BioMed Central Ltd. This is an Open Access article distributed under the terms of the Creative Commons Attribution License (http://creativecommons.org/licenses/by/2.0), which permits unrestricted use, distribution, and reproduction in any medium, provided the original work is properly cited. 
rs600753) to be associated in a female subgroup and the haplotype was associated with short-term memory in quantitative trait analyses, although no associations have been found with DD. In addition, other studies have also reported negative associations [13-16].

Despite these inconsistent findings, DYX1C1 has been shown to play a molecular role in brain development. Knocking down the function of DYX1C1 using small interfering RNA (siRNA) resulted in disruption of normal neuronal migration in the developing neocortex of embryonic rat, which could be reversed by the concurrent overexpression of $D Y X 1 C 1$ [17]. Disruption of DYX1C1 also impaired auditory processing and spatial learning in rodent models [18]. Furthermore, targeted knock down of other dyslexia susceptibility candidate genes (such as KIAA0319 and DCDC2) resulted in similar patterns of neuronal migration $[19,20]$.

To elucidate the role of DYX1C1 in neuronal migration, its interacting protein partners were investigated. Three transcriptional factors sTFII-I, SFPQ and PARP1 bind to the promoter region of $D Y X 1 C 1$ and regulate its expression [21]. The electrophoretic mobility shift assay results suggested they trans-activate the allele -3G of rs3743205 and the binding was weak in the presence of the $-3 \mathrm{~A}$ allele. In addition, two estrogen receptors (ERs), alpha (ERa) and beta (ERb) bind to the p23 domain in the N-terminus of $D Y X 1 C 1$ [22], while heat shock proteins Hsp70 and Hsp90 bind to the TPR domains in its C-terminus [23]. In fact, over-expression of DYX1C1 affects ERa and ERb levels in a dose-dependent manner [22]. Most importantly, the functional roles of ER and its ligand (estradiol) on brain development [24], synaptic plasticity/cognition, neuroprotection [25], and memory and learning [26] have been strongly supported by extensive reviews.

To our knowledge, all current association studies on DD were performed in Caucasian populations, with no information available for non-Caucasian dyslexic cohorts. As the prevalence rate of development dyslexia in Hong Kong Chinese school-aged children was estimated to be between $9.7 \%$ and $12.6 \%$, similar to the rate in Caucasian populations [27], study of the genetic component of dyslexia in Chinese is necessarily important. The Chinese language is known to be substantially different from Western languages, being logographic and morphosyllabic rather than being based on an alphabet [28]. Moreover, orthographic (rather than phonological) deficits were found to be the main problem for Chinese people with dyslexia, in contrast to Caucasians $[29,30]$. fMRI studies of Chinese people with dyslexia also revealed different biological abnormalities in their brains [31,32]. We hypothesize that Chinese people with dyslexia may be influenced by risk alleles in $D Y X 1 C 1$, and we investigated this through genotyping eight genetic variants in 393 individuals from 131 Chinese families with dyslexia.

\section{Materials and methods Subjects}

In total, 393 individuals from 131 Chinese families were recruited with informed consent. This study was approved by the ethical committee of The Chinese University of Hong Kong. Each family consisted of one dyslexic child, with a total of 95 males and 36 females, aged between 5 and 16 years (mean $=8.68 \pm 2.06$ years). They were diagnosed as DD using the Hong Kong Test of Specific Learning Difficulties in Reading and Writing (HKT-SpLD) [33] and referred by the local education authority, child assessment centres, and a parent association. The HKT-SpLD battery consisted of 12 subtests. The subtest are broken down into three literacy tests, which are Chinese Word Reading, One-minute Reading and Chinese Word Dictation, and one rapid naming test, where subjects were asked to name digits, colours and pictures. Two subtests are phonological awareness which tests the subjects' awareness of onset and rhymes of Chinese words, and three phonological memory subtests where subjects are asked to repeat orally the syllables presented to them from a tape recorder. The final three subtests are a test of orthographic skills. This consists of 70 simple Chinese integrated characters and Arabic numbers. Half of them were left/right reversed and the subjects were asked to cross out all items with an incorrect orientation.

These 12 subtests were combined to yield five composite scores in the domains of literacy, phonological awareness, phonological memory, rapid naming and orthographic skills. The sample characteristics of these phenotypic measures are shown in table 1 . To be classified as children with dyslexia, their literacy composite score and at least one cognitive composite score had to be at least one standard deviation $(\mathrm{SD}=3)$ below the means $($ mean $=10)$ of their respective ages in the HKTSpLD (cutoff score $=7$ ). Participants in the dyslexic group fulfilled this diagnostic criterion and all of the subjects showed a normal intelligence on Raven's Standard Progressive Matrices (with IQs of 85 or above).

\section{SNP markers selection}

SNPs were selected from the DYX1C1 region spanning Chr15: 55,709,952 to 55,800,431 (Genome Reference Consortium Human Build 37, NC_000015.9). Six tag SNPs were selected using the TAGGER program as implemented in HaploView 4.1 [34] with parameters of minor allele frequency over $5 \%$ and pairwise $r^{2}$ threshold of 0.8 , based on the population of Han Chinese genotype data generated by the HapMap project (Data Rel\#22/phase II Apr 07). Two previously reported SNPs, rs3743205 (-3G > A) 
Table 1 Descriptive statistics of the HKT-SpLD subtests in the samples.

\begin{tabular}{lcc}
\hline Composite Tests & Sub-tests & Mean Scaled Scores ( \pm SD)* \\
\hline Literacy & Chinese Word Reading & $5.36(2.18)$ \\
& One Minute Reading & $5.52(1.93)$ \\
& Chinese Word Dictation & $4.27(1.89)$ \\
\hline Rapid Naming & Digit Rapid Naming & $5.08(2.98)$ \\
\hline Phonological Awareness & & $9.18(3.11)$ \\
& Rhyme Detection & $9.03(3.04)$ \\
\hline Phonological Memory & Onset Detection & $8.84(3.55)$ \\
& Word Repetition I & $9.09(3.64)$ \\
\hline Orthographic Skills & Non-word Repetition & $9.28(3.28)$ \\
\hline
\end{tabular}

*Scaled score: Mean $=10,1$ S.D. $=3$.

and rs57809907 (1249G > T), were also included in this study [8].

\section{DNA extraction and genotyping}

Two milliliters of saliva was collected from each individual and genomic DNA was extracted using the Oragene ${ }^{\mathrm{TM}}$ DNA self-collection kit following the manufacturer's instructions (DNA Genotek, Inc., Ottawa, Canada). The concentration of the DNA was determined by Quant-iT ${ }^{\mathrm{TM}}$ DNA Assay Kit, Broad Range (Invitrogen Corporation, California, USA). Genotyping was performed using Sequenom ${ }^{\circledR}$ MassARRAY ${ }^{\circledR}$ iPLEX Gold assay, according to the manufacturer's instructions (Sequenom ${ }^{\circledR}$, San Diego, CA, USA, http://www.sequenom.com). Briefly, 5 ng genomic DNA was first amplified to determine the genomic sequence containing the SNP. The unincorporated dNTPs in the PCR reaction was dephosphorylated by shrimp alkaline phosphatase treatment. This is followed by the iPLEX primer extension reaction to generate allele-specific extension products of different mass. The extension products were cleaned using SpectroClean resin and then dispensed onto SpectroCHIP bioarray. The products were detected using MALDI-TOF mass spectrometry and results were analyzed using SpectroTYPER software. Markers were checked for Mendelian inconsistencies and tests of HardyWeinberg equilibrium using Pedstats [35].

\section{Statistical analyses}

Family-based and haplotype association analyses were performed using UNPHASED (Version 3.1.2) which employs an allelic likelihood ratio test [36]. Haplotype analysis was performed using 2- or 3- markers sliding windows method. Initially, a global analysis was performed to test for haplotypic association and then the significant haplotypes were subsequently tested for individual haplotype analysis. Haplotypes with frequencies $<1 \%$ in the whole sample were excluded. The analysis option of conditioning markers was selected for testing direct association of a single marker in the significant haplotypes. Multiple testing was corrected using Qvalue software based on false discovery rates [37]. Permutation test (1000 runs) was also used to run multiple testing corrections over all tests performed in single-marker association analyses of categorical DD. Linkage disequilibrium (LD) was calculated and LD plots were generated using Haploview version $4.1 \mathrm{http}: / /$ www.broad.mit.edu/mpg/haploview[34].

\section{Results}

\section{Single marker analysis}

The call rate of genotyping was least $96 \%$ and Mendelian inconsistencies made up about $0.85 \%$ of the data. Genotypes of Mendelian error were eventually excluded from the analysis. Single marker association showed that SNPs rs3743205 ( $\mathrm{p}=0.0009, \mathrm{OR}=0.08,95 \% \mathrm{CI}=0.01$ to 0.64$)$ and $\mathrm{rs} 4774768(\mathrm{p}=0.0367, \mathrm{OR}=1.68,95 \% \mathrm{CI}=1.02$ to 2.76) were significantly associated with categorical DD (Table 2) in a family cohort. Only rs3743205 remained significant after multiple correction with FDR $(\mathrm{q}=0.0072)$ and 1000 runs of permutation tests (adjusted p = 0.002997 ). Given the significant association of rs3743205 with categorical DD, quantitative trait analysis of literacy and cognitive skills was also tested (Table 3). rs3743205 was associated with literacy (one minute reading: $\mathrm{p}=$ 0.0087, $\mathrm{q}=0.0289)$, rapid naming $(\mathrm{p}=0.0079, \mathrm{q}=0.0289)$, phonological memory (non-word repetition: $\mathrm{p}=0.0096$, $\mathrm{q}=0.0289$ ) and orthographic skills (left-right reversal: 
Table 2 Single-marker analysis between SNPs and categorical DD

\begin{tabular}{|c|c|c|c|c|c|c|c|c|}
\hline rs Number & SNP & Position & Location & Allele & $\mathrm{F}$ & OR $(95 \% \mathrm{Cl})$ & Nominal $p$-value & FDR q-value \\
\hline \multirow[t]{2}{*}{ rs8040756 } & $\mathrm{A} / \mathrm{G}$ & 26589156 & Intron 1 & $A^{*}$ & 0.135 & $1.43(0.88-2.32)$ & 0.1445 & 0.2823 \\
\hline & & & & G & 0.865 & & & \\
\hline \multirow[t]{2}{*}{ rs3743205 } & $\mathrm{G} / \mathrm{A}$ & 26581087 & 5' UTR & $\mathrm{G}^{*}$ & 0.982 & $0.08(0.01-0.64)$ & 0.0009 & 0.0072 \\
\hline & & & & A & 0.018 & & & \\
\hline \multirow[t]{2}{*}{ rs4255730 } & $\mathrm{C} / \mathrm{T}$ & 26578338 & Intron 3 & $C^{*}$ & 0.670 & $0.85(0.59-1.23)$ & 0.3969 & 0.6202 \\
\hline & & & & $\mathrm{T}$ & 0.330 & & & \\
\hline \multirow[t]{2}{*}{ rs692646 } & $\mathrm{A} / \mathrm{G}$ & 26557344 & Intron 4 & $A^{*}$ & 0.067 & $2.00(0.96-4.12)$ & 0.0532 & 0.1385 \\
\hline & & & & G & 0.933 & & & \\
\hline \multirow[t]{2}{*}{ rs692691 } & $\mathrm{C} / \mathrm{T}$ & 26551132 & Intron 4 & $C^{*}$ & 0.947 & $0.86(0.40-1.85)$ & 0.6947 & 0.8455 \\
\hline & & & & $\mathrm{T}$ & 0.053 & & & \\
\hline \multirow[t]{2}{*}{ rs2290981 } & $A / G$ & 26550245 & Intron 4 & $A^{*}$ & 0.119 & $1.10(0.60-2.02)$ & 0.7575 & 0.8455 \\
\hline & & & & G & 0.881 & & & \\
\hline \multirow[t]{2}{*}{ rs4774768 } & $\mathrm{G} / \mathrm{T}$ & 26517062 & Intron 8 & $\mathrm{G}^{*}$ & 0.189 & $1.68(1.02-2.76)$ & 0.0367 & 0.1385 \\
\hline & & & & $\mathrm{T}$ & 0.811 & & & \\
\hline \multirow[t]{2}{*}{ rs57809907 } & $\mathrm{G} / \mathrm{T}$ & 26513439 & Exon 10 & $T^{*}$ & 0.004 & $1.00(0.06-15.99)$ & 1.0000 & 0.9766 \\
\hline & & & & G & 0.996 & & & \\
\hline
\end{tabular}

$\mathrm{F}=$ Allele frequency.

*Reference allele.

$\mathrm{p}=0.0087, \mathrm{q}=0.0289)$. The allele A of rs3743205 was under-transmitted in families with a dyslexic child.

\section{Haplotype analyses}

The four haplotypes rs804075-rs3743205, rs3743205rs4255730, rs692646-rs692691 and rs8040756rs3743205-rs4255730 were significantly associated with categorical DD after corrections for multiple testing (Table 4). Their linkage disequilibrium (LD) structures are shown in Figure 1. Except for the rs692646-rs692691 haplotype $\left(r^{2}=0.702\right.$ between the two SNPs), all other haplotypes consisted of SNPs in low LD $\left(r^{2}<0.5\right)$. Individual haplotype analyses revealed the associated alleles in each haplotype: rs804075-rs3743205 (A-A, p = 0.0005), rs3743205-rs4255730 (A-T, p = 0.0039), rs692646rs692691 (A-C, $\mathrm{p}=0.0067$ ) and rs8040756-rs3743205rs4255730 (A-A-T, p = 0.0009). All the haplotypes which were significantly associated with categorical DD except rs692646-rs692691 were made up of the rs3743205 and had the same allele A found in single marker analysis.

Table 3 Quantitative analysis of rs3743205 in HKT-SpLD tests

\begin{tabular}{|c|c|c|c|}
\hline Tested area & Tests & Nominal $p$-value & FDR (q-value) \\
\hline \multicolumn{4}{|l|}{ Literacy } \\
\hline & Chinese Word Reading (CWR) & 0.5415 & 0.5445 \\
\hline & One Minute Reading (OMR) & 0.0087 & 0.0289 \\
\hline & Chinese Word Dictation (CWD) & 0.5273 & 0.5445 \\
\hline Rapid Naming & Digit Rapid Naming (DRN) & 0.0079 & 0.0289 \\
\hline \multicolumn{4}{|c|}{ Phonological Awareness } \\
\hline & Rhyme Detection (RD) & 0.1105 & 0.2106 \\
\hline & Onset Detection (OD) & 0.5445 & 0.5445 \\
\hline \multicolumn{4}{|c|}{ Phonological Memory } \\
\hline & Word Repetition I (WRI) & 0.0474 & 0.1138 \\
\hline & Non-word Repetition (NWR) & 0.0096 & 0.0289 \\
\hline & Word repetition II (WRII) & 0.1229 & 0.2106 \\
\hline \multicolumn{4}{|c|}{ Orthographic Skills } \\
\hline & Left-Right Reversal (LRR) & 0.0087 & 0.0289 \\
\hline & Lexical Decision (LD) & 0.3002 & 0.4002 \\
\hline & Radical Position (RP) & 0.1481 & 0.2222 \\
\hline
\end{tabular}


Table 4 Results of the haplotype analysis using 2- or 3-markers sliding windows

\begin{tabular}{|c|c|c|c|c|c|c|c|c|}
\hline & \multirow[t]{2}{*}{ Haplotypes } & & \multirow[t]{2}{*}{ Frequency } & \multicolumn{2}{|c|}{ Global tests } & \multicolumn{2}{|c|}{$\begin{array}{c}\text { Individual } \\
\text { haplotype test }\end{array}$} & \multirow{2}{*}{$\begin{array}{c}\text { Testing direct association using conditioning } \\
\text { markers option } \\
\text { p-values }\end{array}$} \\
\hline & & & & $\begin{array}{c}\mathrm{p}- \\
\text { values }\end{array}$ & $\begin{array}{l}\text { FDR (q- } \\
\text { value) }\end{array}$ & $\begin{array}{l}\text { OR }(95 \% \\
\quad \mathrm{Cl})\end{array}$ & $\begin{array}{c}\mathrm{p}- \\
\text { values }\end{array}$ & \\
\hline \multirow{13}{*}{$\begin{array}{c}2- \\
\text { markers }\end{array}$} & rs8040756-rs3743205 & $A-G$ & 0.123 & 0.0002 & 0.0033 & Ref & 0.6803 & 0.7814 \\
\hline & & $A-A$ & 0.026 & & & $N A^{*}$ & 0.0005 & rs3743205 as conditioning marker \\
\hline & & G-G & 0.851 & & & $\begin{array}{l}0.93(0.54- \\
1.60)\end{array}$ & 0.2568 & \\
\hline & rs3743205-rs4255730 & $\mathrm{G}-\mathrm{C}$ & 0.659 & 0.0073 & 0.0255 & Ref & 0.3972 & 0.7593 \\
\hline & & $\mathrm{G}-\mathrm{T}$ & 0.315 & & & $\begin{array}{l}0.94(0.65- \\
1.38)\end{array}$ & 0.9244 & rs3743205 as conditioning marker \\
\hline & & $A-T$ & 0.026 & & & $\begin{array}{l}0.09(0.01- \\
0.69)\end{array}$ & 0.0039 & \\
\hline & rs4255730-rs692646 & & & & NS & & & \\
\hline & rs692646-rs692691 & $\mathrm{G}-\mathrm{C}$ & 0.924 & 0.0118 & 0.0329 & Ref & 0.0555 & 0.0031 rs692691 as conditioning marker \\
\hline & & $A-C$ & 0.021 & & & $\begin{array}{l}0.10(0.01- \\
0.76) \\
\end{array}$ & 0.0067 & 0.0232 rs692646 as conditioning marker \\
\hline & & $A-T$ & 0.055 & & & $\begin{array}{l}0.78(0.35- \\
1.78)\end{array}$ & 0.6831 & \\
\hline & rs692691-rs2290981 & & & & NS & & & \\
\hline & rs2290981-rs4774768 & & & & NS & & & \\
\hline & rs4774768-rs57809907 & & & & NS & & & \\
\hline \multirow[t]{10}{*}{$\begin{array}{c}\text { 3- } \\
\text { markers }\end{array}$} & $\begin{array}{c}\text { rs8040756-rs3743205- } \\
\text { rs4255730 }\end{array}$ & $\begin{array}{c}\text { A-G- } \\
\mathrm{C} \\
\end{array}$ & 0.008 & 0.0019 & 0.0131 & $N A^{\#}$ & & $\begin{array}{c}0.6099 \\
\text { rs3743205 as conditioning marker }\end{array}$ \\
\hline & & $\begin{array}{c}\text { A-G- } \\
\mathrm{T} \\
\end{array}$ & 0.110 & & & $\begin{array}{l}0.99(0.56- \\
1.77) \\
\end{array}$ & 0.1828 & \\
\hline & & $\begin{array}{l}\mathrm{A}-\mathrm{A}-\mathrm{-} \\
\mathrm{T} \\
\end{array}$ & 0.024 & & & $N A^{*}$ & 0.0009 & \\
\hline & & $\begin{array}{l}\mathrm{G}- \\
\mathrm{G}-\mathrm{C} \\
\end{array}$ & 0.654 & & & Ref & 0.3361 & \\
\hline & & $\begin{array}{l}\mathrm{G}- \\
\mathrm{G}-\mathrm{T}\end{array}$ & 0.204 & & & $\begin{array}{c}0.87(0.55- \\
1.36)\end{array}$ & 0.7459 & \\
\hline & $\begin{array}{c}\text { rs3743205-rs4255730- } \\
\text { rs692646 }\end{array}$ & & & & NS & & & \\
\hline & $\begin{array}{c}\text { rs4255730-rs692646- } \\
\text { rs692691 }\end{array}$ & & & & NS & & & \\
\hline & $\begin{array}{c}\text { rs692646-rs692691- } \\
\text { rs22290981 }\end{array}$ & & & & NS & & & \\
\hline & $\begin{array}{c}\text { rs692691-rs2290981- } \\
\text { rs47744768 }\end{array}$ & & & & NS & & & \\
\hline & $\begin{array}{c}\text { rs2290981-rs47747768- } \\
\text { rs57809907 }\end{array}$ & & & & NS & & & \\
\hline
\end{tabular}




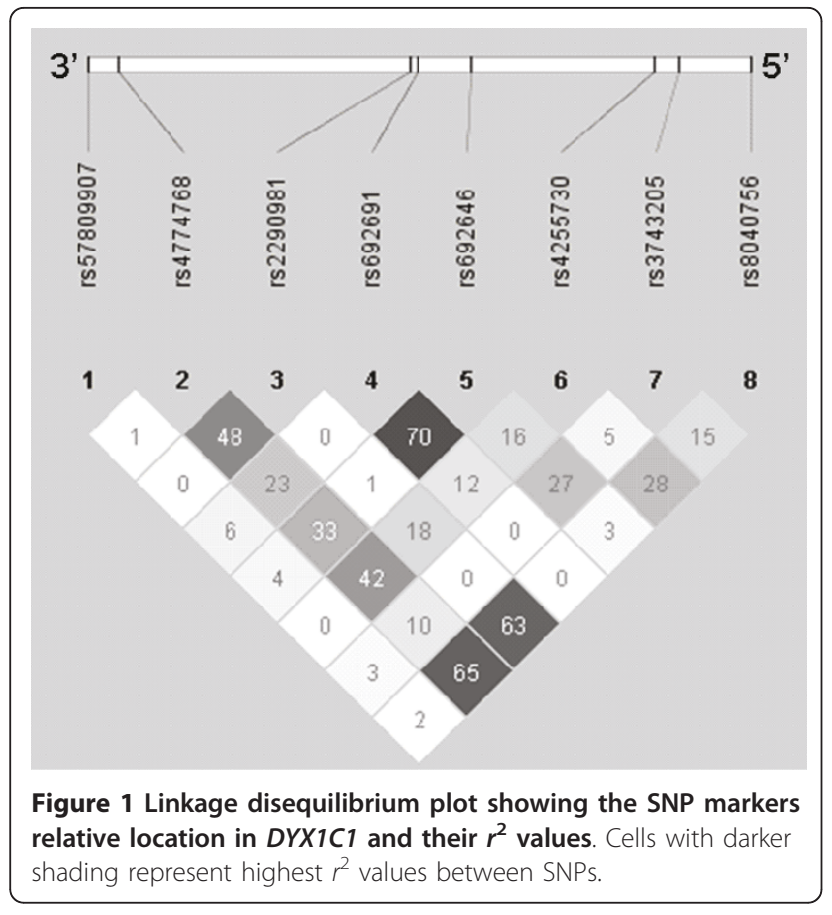

Direct association of the markers with the rs3743205 haplotype was tested using conditioning markers option of the software. All haplotypes consisting of the rs3743205 became insignificant associated with categorical DD after testing using conditioning markers (rs804075-rs3743205/p $=0.7814, \mathrm{rs} 3743205-\mathrm{rs} 4255730 / \mathrm{p}$ $=0.7593$, rs8040756-rs3743205-rs4255730/p = 0.6099). With the exception of rs692646-rs692691 which was still significant whether $\mathrm{rs} 692646(\mathrm{p}=0.0031)$ or rs692691 $(\mathrm{p}=0.0232)$ was set as a conditioning marker. These significant haplotypes were subsequently tested for quantitative trait analyses (Table 5). Both rs3743205-rs4255730 and rs692646-rs692691 haplotypes were associated with skills of literacy (one minute reading), rapid naming, phonological memory (non-word repetition) and orthographic skills (left-right reversal) $(0.01<p<0.03)$. The rs692646-rs692691 haplotype was also associated with phonological awareness (rhyme detection). However, none of the haplotypes remained significant after multiple testing corrections. There are reports of haplotype rs3743205-rs57809907 (-3G > A-1249G > T) testing in the literature, but this was not tested here in the present study because the minor allele frequency (MAF) of rs57809907 was too low $\left(\mathrm{T}_{\mathrm{MAF}}=0.004\right)$ in our samples.

\section{Discussion}

In this study, we demonstrated that SNP rs3743205 was associated with categorical DD in a Chinese cohort. The common allele -3G was over-transmitted in our cohort. Haplotype analysis also showed significant association with categorical DD and most associated haplotypes contain the rs3743205 allele. However, testing for direct association of the markers in the haplotypes showed that they were mainly driven by the effect of rs3743205. Therefore, only the rs692646-rs692691 haplotype showed a combined effect of two SNPs. Taipale et al. [8] reported rs3743205 to be associated with categorical DD but the rarer variant A was over-transmitted in children with dyslexia. Marino et al. [9] found the same direction of transmission as reported by Taipale et al. [8] but this was only marginally significant and was only found in the -3A/1249T haplotype. Wigg et al. [10] reported the opposite preferential transmissions of the common alleles in the -3G/1249G haplotype but the significant associated single-marker was rs11629841. Dahdouh et al. [12] only reported the $-3 G$ containing haplotype G/G/G at rs3743205/rs3743204/rs600753 in female dyslexics.

Dahdouh et al. [12] suggested that this discrepancy of associated variant (A or G) might be due to independent mutation events at $D Y X 1 C 1$, in which the common allele $\mathrm{G}$ is a putative $D Y X 1 C 1$-causing mutation in Central Europeans $[10,11]$, whereas it points to a rarer allele $\mathrm{A}$ in the Finnish and the Italian populations $[8,9]$.

Over-transmission of allele G reported in this study implies the under-transmission of allele A. Concordant to our result, a molecular study showed that the A allele of rs3743205 (-3G/A) can regulate DYX1C1 expression [21]. Using electrophoretic mobility shift assays, Tapia-Paez et al. [21] showed that the A allele probe had lower

Table 5 The significant haplotypes tested with quantitative traits analysis

\begin{tabular}{|c|c|c|c|c|c|c|c|c|c|c|c|}
\hline & \multicolumn{3}{|c|}{ Literacy } & \multirow{2}{*}{$\begin{array}{c}\begin{array}{c}\text { Rapid } \\
\text { Naming }\end{array} \\
\text { DRN } \\
\end{array}$} & \multicolumn{2}{|c|}{$\begin{array}{l}\text { Phonological } \\
\text { Awareness }\end{array}$} & \multicolumn{3}{|c|}{ Phonological Memory } & \multicolumn{2}{|c|}{$\begin{array}{l}\text { Orthographic } \\
\text { Knowledge }\end{array}$} \\
\hline & CWR & OMR & CWD & & RD & OD & WR & NWR & WRI & LRR & LD $\mathrm{R}$ \\
\hline \multicolumn{12}{|l|}{ rs8040756-rs3743205 } \\
\hline rs3743205-rs4255730 & & $\begin{array}{c}0.0296 \\
(0.2328)\end{array}$ & & $\begin{array}{c}0.0307 \\
(0.2328)\end{array}$ & & & & $\begin{array}{c}0.0326 \\
(0.2328)\end{array}$ & & $\begin{array}{c}0.0336 \\
(0.2328)\end{array}$ & \\
\hline rs692646 -rs692691 & & $\begin{array}{c}0.0387 \\
(0.2328)\end{array}$ & & $\begin{array}{c}0.0080 \\
(0.2328)\end{array}$ & $\begin{array}{c}0.0246 \\
(0.2328)\end{array}$ & & & $\begin{array}{c}0.0427 \\
(0.2328)\end{array}$ & & $\begin{array}{l}0.0257 \\
(0.2328)\end{array}$ & \\
\hline $\begin{array}{c}\text { rs8040756 -rs3743205 } \\
-r s 4255730\end{array}$ & & & & & & & & & & & \\
\hline
\end{tabular}

Only the significant nominal $p$-values and q-values (brackets) are shown $(p<0.05)$. 
binding affinity for TFII-I, a transcription factor which represses $D Y X 1 C 1$ activity. Moreover, the allele A probe demonstrated increased $D Y X 1 C 1$ expression (measured using luciferase activity) compared to the $G$ allele probe. The results from our and Tapia-Paez et al's study combine to suggest that the A allele of rs3743205 may confer a protective role in the development of dyslexia rather than the $\mathrm{G}$ allele being a causative factor.

In addition, Massinen et al showed that DYX1C1 interact with and regulates the level of ERs in a dosedependent manner [22]. The ERs and estradiol not only impact on normal brain development [24], but also affect neuronal migration [38]. Defective neuronal migration is a key feature of knocking down dyslexia susceptibility candidate genes [17-20]. Therefore, DYX1C1 might be linked with ERs and neuronal migration in causing dyslexia. In particular, genetic variants of DYX1C1 (-3G or -3A allele) might affect DYX1C1 expression and subsequently, the level of ERs. Interestingly, neuronal migration influenced by estrogen was proposed as one of the mechanisms contributing to sexually dimorphic brain characteristics [39-41]. The gender ratio of Hong Kong Chinese is 1.6 males to 2.0 females [27]. Whether boys are more likely than girls to have reading disabilities is still unclear, but this genderrelated mechanism might be the cause of boys being more susceptible to developing dyslexia.

With regard to quantitative traits analyses, rs3743205 was also significantly associated with one minute reading (OMR) of literacy, digit rapid naming (DRN), nonword repetition (NWR) of phonological memory and left-right reversal (LRR) of orthographic skills in this study. In other studies, Marino et al. [9] have reported short-term memory (STM) in linkage disequilibrium with the rarer A allele of $-3 \mathrm{G}>\mathrm{A}$ and a three marker haplotype G/G/G at rs3743205/rs3743204/rs600753 associated with STM only (the subjects in this study were all female) [12]. Recently, Bates et al [42] first reported the association of DYX1C1 polymorphisms with normal reading ability (Regular-word, irregularword and nonword reading and spelling as well as verbal short-term memory) in 790 Australian families. They found that rs17819126 was significantly associated with all three reading measures and irregular word spelling. There was a marginal association with rs3743204 and irregular word reading and significant association with nonword reading. Also, a measure of verbal shortterm memory was significantly associated with rs685935. However, neither rs3743205 nor rs57809907 previously reported by Taipale et al. [8] was significantly associated with any measures in the study of Bates et al. [42].

In the HKT-SpLD used in this study, the one minute reading (OMR) measures Chinese word reading fluency, the digit rapid naming (DRN) reflects long term learning ability of visual-verbal associations, and non-word repetition (NWR) is defined as a form of phonological shortterm memory. Therefore, OMR measured in this study may approximate the skills required for regular word reading, skills measured by DRN may be similar to the acquisition of grapheme-phoneme conversion rules required in non-word reading, and NWR is similar to the verbal short-term memory in the study of Bates et al. [42]. In the view of associated traits, it is reasonable to suggest that our results of quantitative traits analyses closely agree with the findings of Bates et al. [42] but in different variants of $D Y X 1 C 1$.

Although the significant SNPs (rs3743204, rs685935 and rs17819126) reported by Bates et al. [42] were not genotyped in this study, the rs8040756 and rs 4774768 examined in this study were in linkage disequilibrium with rs3743204 and rs685935 respectively (Han Chinese Hapmap data: r8040756-rs3743204 $r^{2}=1$, rs4774768rs685935 $r^{2}=0.9$ ). These tag SNPs (rs8040756 and rs4774768) examined in this study are supposed to capture the alleles of rs3743204 and rs685935. Moreover, rs17819126 missense variation is unique in populations of European origin as shown by the minor allele frequency based on the Hapmap data is about 9\% in a Utah population, $1 \%$ in Yoruba, but only $0.5 \%$ in Japanese and $0.7 \%$ in Chinese. It is worth noting that none of the eight tag SNPs based on the Chinese population was significantly associated with DD or phenotypic traits in this study, with the exception of the previously reported rs3743205. rs3743205 was not a selected tag SNP and its allele frequency $(<0.05)$ is beyond the threshold of it being powerful enough to detect associations of the tag SNPs genotyped in this study. Therefore, we could not rule out the association of rs17819126 that was not captured by current tag SNP markers. In addition, these results indicate that Chinese reading-related skills are associated with rare variants of DYX1C1 in the Chinese population. Further study using markers of rare variant (MAF < 0.05) might support this finding.

When taken together, DYX1C1 is suggested to be associated with Chinese dyslexia, and Chinese literacy and cognitive skills (DRN, NWR and LRR). These cognitive skills are all important reading-related skills in readers of the Chinese language and rapid naming and orthographic deficits were characterized as the main cognitive problems in Chinese dyslexic children $[30,43,44]$. To the best of our knowledge, this is the first genetic study showing that DYX1C1 is also a candidate dyslexia susceptibility gene for Hong Kong Chinese children. Again, we have shown the genetic heterogeneity of dyslexia that different variants of DYX1C1 may be associated with dyslexia in different populations. The existence of any population- and/or language-based variant in dyslexia should be clarified in future association studies. In particular, 
studies of other dyslexia candidate genes in Chinese are essential to provide us with a more complete picture of the universality of genetic association in dyslexia.

\begin{abstract}
Acknowledgements
This work was partly supported by donations from the Croucher Foundation awarded to MW. We thank Amabel Wong and Helen Chan for their technical assistance with genotyping experiments. We also thank all the families and volunteers who participated, the Hong Kong Association for Specific Learning Disabilities and the Child Assessment Service (Department of Heath) for their assistance in subject recruitment.
\end{abstract}

\section{Author details}

'Croucher Laboratory for Human Genomics, School of Biomedical Sciences, The Chinese University of Hong Kong, Shatin, N.T, Hong Kong. ${ }^{2}$ Department of Psychology, The University of Hong Kong, Hong Kong.

\section{Authors' contributions}

MW designed the study and supervised the overall experimental part of the project, communicated with the Association of Specific learning disability for help with recruitment of the subjects. $\mathrm{CH}$ supervised gathering the reading and writing performance and development of classification schemes for the dyslexic children, and communicated with Government departments and other agencies to obtain details of the phenotypes. CC assembled and input the test scores of the dyslexic children. $\mathrm{CL}$ designed and performed all the genotype analyses and association analyses of risk alleles. All authors discussed the results and implications and commented on the manuscript at all stages.

\section{Competing interests}

MW is a consultant of Genetic Centre Company Limited, Hong Kong. CL is the Laboratory Director of Multigene Diagnostics Limited, Hong Kong.

Received: 21 February 2011 Accepted: 20 May 2011

Published: 20 May 2011

\section{References}

1. Lerner JW: Educational interventions in learning disabilities. J Am Acad Child Adolesc Psychiatry 1989, 28(3):326-331.

2. Shaywitz SE: Dyslexia. N Engl J Med 1998, 338(5):307-312.

3. Shastry BS: Developmental dyslexia: an update. J Hum Genet 2007, 52(2):104-109.

4. Anthoni H, Zucchelli M, Matsson H, Muller-Myhsok B, Fransson I, Schumacher J, Massinen S, Onkamo P, Warnke A, Griesemann H, Hoffmann P, Nopola-Hemmi J, Lyytinen H, Schulte-Korne G, Kere J, Nothen MM, Peyrard-Janvid M: A locus on 2p12 containing the coregulated MRPL19 and C2ORF3 genes is associated to dyslexia. Hum Mol Genet 2007, 16(6):667-677.

5. Couto JM, Gomez L, Wigg K, Cate-Carter T, Archibald J, Anderson B, Tannock R, Kerr EN, Lovett MW, Humphries T, Barr CL: The KIAA0319-like (KIAA0319L) gene on chromosome $1 \mathrm{p} 34$ as a candidate for reading disabilities. J Neurogenet 2008, 22(4):295-313.

6. Ludwig KU, Roeske D, Herms S, Schumacher J, Warnke A, Plume E, Neuhoff N, Bruder J, Remschmidt H, Schulte-Korne G, Muller-Myhsok B, Nothen MM, Hoffmann P: Variation in GRIN2B contributes to weak performance in verbal short-term memory in children with dyslexia. Am J Med Genet B Neuropsychiatr Genet 2010, 153B(2):503-511.

7. Nopola-Hemmi J, Taipale M, Haltia T, Lehesjoki AE, Voutilainen A, Kere J: Two translocations of chromosome $15 q$ associated with dyslexia. J Med Genet 2000, 37(10):771-775.

8. Taipale M, Kaminen N, Nopola-Hemmi J, Haltia T, Myllyluoma B, Lyytinen H, Muller K, Kaaranen M, Lindsberg PJ, Hannula-Jouppi K, Kere J: A candidate gene for developmental dyslexia encodes a nuclear tetratricopeptide repeat domain protein dynamically regulated in brain. Proc Natl Acad Sci USA 2003, 100(20):11553-11558.

9. Marino C, Citterio A, Giorda R, Facoetti A, Menozzi G, Vanzin L, Lorusso ML, Nobile M, Molteni M: Association of short-term memory with a variant within DYX1C1 in developmental dyslexia. Genes Brain Behav 2007, 6(7):640-646.
10. Wigg KG, Couto JM, Feng Y, Anderson B, Cate-Carter TD, Macciardi F, Tannock R, Lovett MW, Humphries TW, Barr CL: Support for EKN1 as the susceptibility locus for dyslexia on 15q21. Mol Psychiatry 2004, 9(12):1111-1121.

11. Scerri TS, Fisher SE, Francks C, MacPhie IL, Paracchini S, Richardson AJ, Stein JF, Monaco AP: Putative functional alleles of DYX1C1 are not associated with dyslexia susceptibility in a large sample of sibling pairs from the UK. J Med Genet 2004, 41(11):853-857.

12. Dahdouh F, Anthoni H, Tapia-Paez I, Peyrard-Janvid M, Schulte-Korne G, Warnke A, Remschmidt H, Ziegler A, Kere J, Muller-Myhsok B, Nothen MM, Schumacher J, Zucchelli M: Further evidence for DYX1C1 as a susceptibility factor for dyslexia. Psychiatr Genet 2009, 19(2):59-63.

13. Cope N, Hill G, van den Bree M, Harold D, Moskvina V, Green EK, Owen MJ, Williams J, O'Donovan MC: No support for association between dyslexia susceptibility 1 candidate 1 and developmental dyslexia. Mol Psychiatry 2005, 10(3):237-238.

14. Bellini $G$, Bravaccio C, Calamoneri F, Donatella Cocuzza M, Fiorillo P, Gagliano A, Mazzone D, del Giudice EM, Scuccimarra G, Militerni R, Pascotto A: No evidence for association between dyslexia and DYX1C1 functional variants in a group of children and adolescents from Southern Italy. J Mol Neurosci 2005, 27(3):311-314.

15. Meng H, Hager K, Held M, Page GP, Olson RK, Pennington BF, DeFries JC, Smith SD, Gruen JR: TDT-association analysis of EKN1 and dyslexia in a Colorado twin cohort. Hum Genet 2005, 118(1):87-90.

16. Brkanac Z, Chapman NH, Matsushita MM, Chun L, Nielsen K, Cochrane E, Berninger WW, Wijsman EM, Raskind WH: Evaluation of candidate genes for DYX1 and DYX2 in families with dyslexia. Am J Med Genet B Neuropsychiatr Genet 2007, 144B(4):556-560.

17. Rosen GD, Bai J, Wang Y, Fiondella CG, Threlkeld SW, LoTurco JJ, Galaburda AM: Disruption of neuronal migration by RNAi of Dyx1c1 results in neocortical and hippocampal malformations. Cereb Cortex 2007, 17(11):2562-2572.

18. Threlkeld SW, McClure MM, Bai J, Wang Y, LoTurco JJ, Rosen GD, Fitch RH: Developmental disruptions and behavioral impairments in rats following in utero RNAi of Dyx1c1. Brain Res Bull 2007, 71(5):508-514.

19. Paracchini S, Thomas A, Castro S, Lai C, Paramasivam M, Wang Y, Keating BJ, Taylor JM, Hacking DF, Scerri T, Francks C, Richardson AJ, WadeMartins R, Stein JF, Knight JC, Copp AJ, Loturco J, Monaco AP: The chromosome 6 p22 haplotype associated with dyslexia reduces the expression of KIAA0319, a novel gene involved in neuronal migration. Hum Mol Genet 2006, 15(10):1659-1666.

20. Meng H, Smith SD, Hager K, Held M, Liu J, Olson RK, Pennington BF, DeFries JC, Gelernter J, O'Reilly-Pol T, Somlo S, Skudlarski P, Shaywitz SE, Shaywitz BA, Marchione K, Wang Y, Paramasivam M, LoTurco JJ, Page GP, Gruen JR: DCDC2 is associated with reading disability and modulates neuronal development in the brain. Proc Natl Acad Sci USA 2005, 102(47):17053-17058

21. Tapia-Paez I, Tammimies K, Massinen S, Roy AL, Kere J: The complex of TFIIII, PARP1, and SFPQ proteins regulates the DYX1C1 gene implicated in neuronal migration and dyslexia. FASEB J 2008, 22(8):3001-3009.

22. Massinen S, Tammimies K, Tapia-Paez I, Matsson H, Hokkanen ME, Soderberg O, Landegren U, Castren E, Gustafsson JA, Treuter E, Kere J: Functional interaction of DYX1C1 with estrogen receptors suggests involvement of hormonal pathways in dyslexia. Hum Mol Genet 2009, 18(15):2802-2812.

23. Chen Y, Zhao M, Wang S, Chen J, Wang Y, Cao Q, Zhou W, Liu J, Xu Z, Tong G, Li J: A novel role for DYX1C1, a chaperone protein for both Hsp70 and Hsp90, in breast cancer. J Cancer Res Clin Oncol 2009, 135(9):1265-1276.

24. McCarthy MM: Estradiol and the developing brain. Physiol Rev 2008, 88(1):91-124.

25. Raz L, Khan MM, Mahesh VB, Vadlamudi RK, Brann DW: Rapid estrogen signaling in the brain. Neurosignals 2008, 16(2-3):140-153.

26. Hill RA, Boon WC: Estrogens, brain, and behavior: lessons from knockout mouse models. Semin Reprod Med 2009, 27(3):218-228.

27. Chan DW, Ho CS, Tsang S, Lee S, Chung KKH: Prevalence, Gender Ratio and Gender Differences in Reading-Related Cognitive Abilities among Chinese Children with Dyslexia in Hong Kong. Educational Studies 2007, 33(2):249-265.

28. Ho CS, Bryant P: Learning to read Chinese beyond the logographic phase. Reading Research Quarterly 1997, 32(3):276. 
29. Ho CS, Chan DW, Chung KKH, Lee S, Tsang S: In search of subtypes of Chinese developmental dyslexia. J Exp Child Psychol 2007, 97(1):61-83.

30. Ho CS, Chan DW, Lee S, Tsang S, Luan VH: Cognitive profiling and preliminary subtyping in Chinese developmental dyslexia. Cognition 2004, 91(1):43-75.

31. Siok WT, Niu Z, Jin Z, Perfetti CA, Tan LH: A structural-functional basis for dyslexia in the cortex of Chinese readers. Proc Natl Acad Sci USA 2008, 105(14):5561-5566.

32. Siok WT, Perfetti CA, Jin Z, Tan LH: Biological abnormality of impaired reading is constrained by culture. Nature 2004, 431(7004):71-76.

33. Ho CSH, Chan D, Tsang SM, Lee SH: The Hong Kong Test of Specific Learning Difficulties in Reading and Writing (HKT-SpLD) Manual Hong Kong: Hong Kong Specific Learning Difficulties Research Team; 2000.

34. Barrett JC, Fry B, Maller J, Daly MJ: Haploview: analysis and visualization of LD and haplotype maps. Bioinformatics 2005, 21(2):263-265.

35. Wigginton JE, Abecasis GR: PEDSTATS: descriptive statistics, graphics and quality assessment for gene mapping data. Bioinformatics 2005, 21(16):3445-3447.

36. Dudbridge F: Pedigree disequilibrium tests for multilocus haplotypes. Genet Epidemiol 2003, 25(2):115-121.

37. Storey JD, Tibshirani R: Statistical significance for genomewide studies. Proc Natl Acad Sci USA 2003, 100(16):9440-9445.

38. Wang L, Andersson S, Warner M, Gustafsson JA: Morphological abnormalities in the brains of estrogen receptor beta knockout mice. Proc Natl Acad Sci USA 2001, 98(5):2792-2796.

39. Henderson RG, Brown AE, Tobet SA: Sex differences in cell migration in the preoptic area/anterior hypothalamus of mice. J Neurobiol 1999, 41(2):252-266.

40. Wolfe CA, Van Doren M, Walker HJ, Seney ML, McClellan KM, Tobet SA: Sex differences in the location of immunochemically defined cell populations in the mouse preoptic area/anterior hypothalamus. Brain Res Dev Brain Res 2005, 157(1):34-41.

41. Knoll JG, Wolfe CA, Tobet SA: Estrogen modulates neuronal movements within the developing preoptic area-anterior hypothalamus. Eur J Neurosci 2007, 26(5):1091-1099.

42. Bates TC, Lind PA, Luciano M, Montgomery GW, Martin NG, Wright MJ: Dyslexia and DYX1C1: deficits in reading and spelling associated with a missense mutation. Mol Psychiatry 2010, 15(12):1190-1196.

43. Ho CS, Lai DN: Naming-speed deficits and phonological memory deficits in Chinese developmental dyslexia. Learning and Individual Differences 1999, 11(2):173-186.

44. Ho CS, Law TP, Ng PM: The phonological deficit hypothesis in Chinese developmental dyslexia. Reading and Writing 2000, 13(1):57-79.

doi:10.1186/1744-9081-7-16

Cite this article as: Lim et al:: Association of the rs3743205 variant of DYX1C1 with dyslexia in Chinese children. Behavioral and Brain Functions 2011 7:16.

\section{Submit your next manuscript to BioMed Central and take full advantage of:}

- Convenient online submission

- Thorough peer review

- No space constraints or color figure charges

- Immediate publication on acceptance

- Inclusion in PubMed, CAS, Scopus and Google Scholar

- Research which is freely available for redistribution 